\title{
Driverless, or Carless Future? Socio-technical Scenarios of Autonomous Urban Mobility in the Czech Republic
}

\author{
Daniel Szabóa \\ ${ }^{a}$ Transport Research Centre, Líšeňská 33a, Brno, Czech republic
}

ABSTRACT: The autonomous vehicles are in the phase of prototypes and proofs-of-concept, yet the promises and visions of autonomous future already drive significant changes in long term urban planning. We utilise the socio-technical transition approach to autonomous vehicles' services to help to understand the dynamics of the development and to direct public policies in order to foster a more environmentally and socially sustainable urban mobility. The research uses a three-round Delphi method with experts and stakeholders in the field of research and development to explore potential pathways and develop a multi-level perspective (MLP) socio-technical model of autonomous vehicles' implementation in Czech cities. There already exist stabilising and destabilising pressures within the automobile regimes, closely connected to the autonomous vehicles development, which may result in divergent, more or less disrupting pathways. Considering a varyingly high level of uncertainty in specific regimes, we have developed three diverse socio-technical scenarios: 1. A transformation - 'sceptical-public transport' pathway, barring any significant technological or societal advancements towards autonomous driving in Czech urban context; 2. A reconfiguration'slow incremental development' scenario, in which the incremental progress enables more flexible and effective public transport services, shared mobility and promotes electromobility; and 3. A technological substitution - 'techno-optimist' scenario, relying heavily on fast technological progress towards fully autonomous vehicles without requiring vast additional infrastructure and use of V2X communication. Through analysis of the promising niche innovations and their regimelandscape interactions, the article devises a scope for possible policy actions in order to support more sustainable autonomous mobility development.

KEYWORDS: Multi-level Perspective, Socio-technical Transitions, Connected and Autonomous Vehicles, Urban Mobility, Sustainable mobility

\section{INTRODUCTION}

The looming inevitability of climate disruption and not meeting the greenhouse gas (GHG) emission targets, along with the burden of private passenger vehicles on the public health through air pollution and environmental degradation, is a powerful catalyst for pursuing low- or post-carbon mobility transitions. The most sought for are systemic transformations, that would globally reverse the pathways, where the emissions and resulting disruptions soar even further. Even more challenging is to accomplish this without reducing the benefits of accessibility and the social equity dimensions, associated with the accessibility of mobility. Social equity dimension is too often marginalised, even when planning for seemingly non-problematic modes, such as cycling (Golub, L. Hoffmann, E. Lugo, \& F.Sandoval, 2016) (Sheller, 2015). However, it presses even harder in highly automobile-dependent spatialities, as is highlighted in the concept of 'splintering' urbanism (Graham \& Marvin, 2001). It is also notable in the case of public policies, restricting car use through emission (fuel) charging, such as low-emission zones or the recent origins of the gilet jaunes' movement in a carbon tax on gasoline and diesel. Public resistance against any measures, limiting automobile use, accentuate the paradox of architecture of 'choice' - the coming together of the everyday situated practice of mobility and physical landscape, both built around cars, that made other than automobile choices close to impossible. Furthermore, it becomes resistant, when only a part of the architecture is changed (Barr \& Prillwitz, 2014) - e.g. when automobility as a results of the "green taxation" becomes increasingly expensive and therefore unevenly accessible.

Large-scale deployment of connected and autonomous/automated vehicles (CAVs) or fully au- 
tonomous vehicles (AVs), fit for a wide range of purposes, is one of the possible pathways, alleviating the climate tolls of transportation, while nivellating socio-spatial aspects of mobility equity. The broad spectrum of automated-autonomous vehicles thus is one of the promoted technological responses within the discourse of ambitions to develop alternative sociotechnical arrangements to meet the goals of sustainable, yet accessible and just mobility (Nikolaeva et al., 2019). One that would "bypass" the conundrum of the physical and urban structure-induced (coerced) mobility. On the other hand, the promise of the approaching autonomous future can serve and indeed in many cases serves as an argument to promote investments into technological innovations with dubious impacts on transport system performance and mobility patterns. Such is the case of transportation network companies (TNCs) such as Uber or Lyft, whose operation in effect due to induced automobility and low occupancy significantly worsened congestions in terms of vehicle hours of delay and vehicle miles travelled. The effect has been analysed to a great detail e.g. in the technical report for San Francisco Country Transportation Authority ${ }^{1}$ (Castiglione et al., 2018). TNCs were the most significant contributors to the increased congestions, despite the companies' marketing claims of net positive effect (Roy, 2019).

The promise of autonomous future is also being used to promote suppression or halting of development or sustaining public transport services, presented as - albeit technically incorrectly - ineffective and obsolete (Currie, 2018). (Grush \& Niles, 2018) show, that widespread "hope, hype and exaggeration", currently surrounding the autonomous future can actively mislead planners in terms of reliable predictions, especially given the gap of development between different regions. At the same time, there are indications that autonomous vehicles have already fallen into the 'trough of disillusionment' within the Gartner's 'hype cycle'2, which on the contrary might see the acceptance of the autonomous vehicles' implementation gradually falter in the coming years. Considering that autonomous vehicles might never achieve cost-competitiveness (Nunes \& Hernandez,

\section{Open dataset, accessible from} http://tncsandcongestion.sfcta.org/

2 The observation, that technological innovations in general fall into a curve, where their popularity, based on expectations, highly exceeds its productivity, inevitably resulting in disillusionment, when the prototypes fail to deliver promised results in the short term.
2019) or even the full working level of autonomy, the narrative of autonomous future might shift towards more clear-headed and precautionary, lending space to more nuanced discussion and research. This time-window should aide urban planners in devising well thought-out, rather than rushed implementation plans.

\subsection{Sustainable urban transport planning challenges - a need for a foresight}

In an automobile-oriented development, in the yearto-year urban and transport planning, autonomous mobility can serve as a rationale to delay or avoid interventions to reduce car dependency. On the other hand, it can serve as a powerful impetus to disrupt the dominant model of private mobility (as is suggested even in the Czech Action plan on Autonomous Driving) and bring us closer towards the 'life after the car' (Dennis \& Urry, 2009).

Future visions can serve as a powerful stabilising factor for sustaining certain aspects of the current system - a "promise-contract", "connecting the past futures to the future presents, allowing us to securely navigate through uncertainty" (Adam \& Groves, 2007, pp. 45-48). Geels (Geels, 2014) who has been broadening the sustainability research with insights from political economy, has described, how the currently dominant energy production regimes have for decades formed a coalition ("a regime resistance") against the low-carbon transformation. The coalitions work through the mobilisation of instrumental, material, institutional and discursive strategies, e.g. stressing the importance of energy security and affordability against the climate change mitigation, leveraging the 'structural power', that provides the industry the access to shaping public policies. What the socio-technical scenarios can bring into the discussion, is the very analysis of the dynamics of the transition itself - how will the ambitions towards autonomous mobility shape the existing mobility regimes, especially in terms of public policies and infrastructure investments.

The key questions that arise are thus:

1. What organisational, institutional processes concrete public policies can effectively mitigate the risks of AV deployment?

2. How to consolidate the long-term strategies with short-term policies, locked in the vicious circle of providing adequate infrastructure 
for ever-rising individual mobility? In other words - can the vision of autonomous revolution support also progress towards mass, shared and human-powered mobility, or will it, on the contrary, function as a device of "autopia”, a promise of a seamless future innovation with no trade-offs, thus further propelling large infrastructural investments and car dependency?

3. And what role can the cities adopt in directing and adapting to the transitions?

Given this, developing public policies for urban governance, that would not only foster the growth of new mobility services, technologies and practices but would also steer mobility towards more socially and environmentally sustainable forms is a major challenge for the urban future. The challenge is twofold: the first is to adapt the cities to the new socio-technical forms of mobility that are being promoted by technological research and investment as an exogenous pressure. The second challenge is to adapt the cities to increasingly unpredictable climate patterns and reduce their environmental externalities. In this respect, Autonomous vehicles' revolution might fail to deliver on its promises, even when there is currently little to no political dissensus on its need (such as is presented in the Czech Action Plan on Autonomous Driving), meaning, that other viable alternative sustainability pathways could face an uphill battle due to lack of political and institutional support.

This article thus aims to fill a gap in the literature focused on the large-scale autonomous vehicles transition in the Czech Republic in order to try to foresee the potential dynamics of implementation of various autonomous services. The theoretical approach is to consider the innovation pathways as multi-level interplays of societal, technological and institutional actors and forces. The objective of the research is to aid the urban mobility planners and organisations involved in long-term strategic urban planning. Especially the long-term transport planning on the urban level in the Czech Republic is currently stymied, to a large extent caught in the vicious circle of induced mobility, brought through a specific, spatially and socially uneven post-socialist urban transformation (Altrock, Güntner, Huning, \& Peters, 2019, pp. 118-124). The long-term automobility lock-in hinders the ability to predict and adapt to the longterm landscape changes in urban mobility, that even- tually inevitably bring an end to the predominantly carbon-based mobility. The short-time solutions often resort to ready-made end-of-pipe investments with ambiguous impacts on the overall mobility (Temenos et al., 2017, p. 114-116).

\section{METHODOLOGY}

While this article analyses primarily the development of CAV, even this domain allows wildly diverging paths to envision, depending on factors, such as forms of usership or ownership, market penetration, infrastructure and road network readiness, technological innovation, types of vehicle propulsion, public and pedestrian space, road safety, speed, impacts on employment, accessibility and others. The diverse field of technology and its implementation is the first significant research challenge. The second challenge that is often forgotten in the technological innovation studies is to consider the emerging technology not only by itself, but in a co-evolution and interaction with other technological and societal innovations (organisations, movements) - through competition, cooperation or hybridisation (B Elzen, Geels, \& Hofman, 2002). The research uses multiround Delphi study, consisting of semi-structured questionnaires and discussions, in order to draw from a wide range of expert views and cover various viable paths and explore the existing and emerging networks of relationships.

\subsection{Delphi study principles and considerations}

In order to reduce the common theoretical and practical pitfalls, associated with the method, we conducted the study consistently with the principles, set out in the literature - (Linstone \& Turoff, 1977), (Landeta $\&$ Barrutia, 2011) and (Melander, 2018):

- We set the planning horizon in the near future so as to avoid distortions through cumulating uncertainties or discounting the future (Linstone \& Turoff, 1977, p. 260).

- We conducted the panel timely in direct connection with the development of the public policies of implementation of CAVs in the Czech Republic, therefore allowing the experts to participate on the policies' creation through their reasoned opinions, i.e. raising their stakes. 
- We have constituted the questions in an openended manner in order to minimise the risk of manipulation; the respective topics have been reiterated through series of question, in order to provide space for more nuanced and reasoned answers and avoid optimism bias (Linstone \& Turoff, 1977, pp. 568-569).

- All of the answers contribute to the results to some extent, via developing a wide range of scenarios, providing space for a dissenting spectrum of opinions and values.

- We facilitated a controlled discussion between the experts in order to clarify and expand on the preliminary results.

- A transparent description of the method used and dissemination of the results is provided throughout the project's execution.

- A knowledgeable set of experts has been selected in order to maximise the relevance of the answers.

- We have developed the scenarios based on the experts' responses and then provided them back to being commented on and reaffirmed.

- However, there are also methodological drawbacks that we are trying to account for: especially a low heterogeneity of the experts involved and a low number of experts.

In total, 29 experts have been invited for participation through November - February 2019 with reminders sent in order to increase the return rate, with 13 experts actively participating. The experts have been selected primarily through their previous active participation in Platform for Fully Autonomous Ve- hicles. This Platform consists of five thematic workgroups, founded by Czech Ministry of Transport. It involves experts and stakeholders from the public and private research, directly involved in CAV development or deployment.

\subsection{Structuring the questionnaires}

We framed the first round of the Delphi questionnaire specifically to explore the most dominant trends and services that are emerging and could potentially emerge as dominant within the development and deployment of the autonomous vehicles' technologies. The thematic areas and questions were formulated based on hypotheses, drawn from literature research. The questionnaire was divided into three thematic sections (figure 1).

The experts are encouraged to reason why and how they see these outcomes or relations occurring, as well as to expand on the potential policies, that would address the underlying issues.

A total of 753 answers have been recorded. The qualitative data obtained were open-coded through content analysis to create a set of variables - key issues with categorical (nominal) differentiation - describing experts' view on themes, such as impacts on employment, or public space. These categories were grouped through cluster analysis into three base qualitative scenarios - different storylines for the future.

The second round of the Delphi questionnaire was aimed to more clearly delineate and explore the scenarios, developed in the first round, through a series of specific open-ended questions, aimed at technical,

1. Defining the most dominant autonomous vehicles' services.

2. Exploring legislative, environmental, social, economic, technological and technical benefits, costs, risks and pathways.

3. Defining a potential operating business model for the services through a series of open-ended questions.

Figure 1: Structure of the 1st round of the Delphi study

1. Technological development of CAVs (passive and active safety, sensors, artificial intelligence, functional safety, C-ITS / V2X communication, cybersecurity, traffic management);

2. Public support for CAV development (legislative measures, research support, infrastructure financing, xEV support, changes in ownership and public acceptance)

3. Ethical aspects (cyber attacks, mixed vs segregated traffic, human agency restrictions, data collection, safety criteria and others)

4. Scenario development and transformation (remarks on the scenarios, developed through the first round). 
ethical, legislative, safety, environmental and other aspects of specific socio-technical arrangements, derived from the first round (such as vehicle - vulnerable road users interactions, energy expenditure solutions etc.). The questions were divided into four sections (figure 2).

A total of 223 answers were recorded in the second round.

The participants of the Delphi expert panel were afterwards invited to a $3^{\text {rd }}$ round of the study, that consisted of a round-table discussion, elaborating on the specific topics and controversies that arose in the first two rounds of the Delphi method, more embedded in the context of Czech cities and better time-bound.

\subsection{Analysis}

The analysis is structured as follows:

1. The first section (Chapter $\mathbf{1}$ ) is dedicated to the wider context of the current state of CAVs' deployment in the urban areas.

2. In the second section (Chapter 3) we outline the methods used in developing future scenarios, using data from an expert Delphi panel to develop a multi-level perspective model for probable transition pathways up to the year 2030 .

3. In the third section (Chapter 4) we map the innovation pathways in the Czech context. In this chapter we develop three probable scenarios, based on the analysis of the Delphi study results, and explore dynamics of automated niche innovation advancements and of transition towards the autonomous regime based on the identified higher level interplays.

4. In the fourth section (Chapter 5) we delineate the space for potential policy actions in Czech urban governance to steer and support the transition pathways and potential for future research.

Socio-technical transition (STT) framework and technological innovation system (TIS) (within innovation studies) are two theoretical approaches that dominate the analysis of the dynamics of technological change in social science. The article utilizes the theoretical framework of multi-level perspective (MLP) socio-technical transitions (STT).
The theoretical framework analyses the longterm stability (obduracy) and change (i.e. transition) of socio-technical regimes through a lens of

"evolutionary economics (technological trajectories, regimes, niches, speciation), sociology of technology (innovations are socially constructed through interactions between engineers, firms, consumers, policymakers) and neo-institutional theory (actors are constrained by shared beliefs, norms and regulations)" (Geels, 2012a, p. 472).

We base the primary "(road)mapping" of the multi-level interplays of actors on a three-round Delphi method with experts from the autonomous mobility development. In contrast to the traditional Delphi method, the objective was not to reach a consensus, but to cluster the experts' reasoned views into divergent set of scenarios and through comparison of aspects of the scenarios, such as risks and uncertainties, magnitudes, time horizons, dominant actors, dominant services and market success, to develop a qualitative model of the possible futures, with assessment of the main stabilising factors and potential spaces for reaching a more sustainable system performance

\section{QUALITATIVE DATA COLLECTION: A DELPHI STUDY}

In general, Delphi methods are used as a predictive tool, drawing from knowledge and expertise of experts or other stakeholders through series of reevaluations - iterations, aiming to achieve a convergence of opinions on a complex problem (Turoff, 1970). The Delphi method in this article is utilised not in order to develop socio-technical scenarios as "truths about the future", but rather in order to explore the dynamics of the processes of the potential autonomous mobility transition and on those grounds provide the necessary knowledge to prepare, react, or manage the transition within cities as eventual recipients of the anticipated services.

We conducted the study with the following steps for developing and transferring the scenarios:

1. Mapping the field to explore: Identification of main actors, networks and their interplays in the Czech context; identification of current 
niche, regime and landscape developments through literature research.

2. Utilising the experts: Developing a multilevel network of niche, regime and landscape factors and actors, highlighting key actors, trajectories, dependencies and uncertainties. The qualitative data for the analysis have been obtained through a Delphi study with selected experts, specialising in CAV development.

3. Identifying the transition pathways: based on multi-level interactions, according to Geels and Schot typology and conditions (Geels \& Schot, 2007).

4. Transferring the scenarios: outline of applicability for urban governance.

\subsection{Identification and participation of expert stakeholders}

In technology forecasting, a wide range of methodologies is being used so as to solve the uncertainties, inherent to the complex and highly unpredictable nature of mobility, where expert judgment is considered as considerably reliable (Melander, 2018). The article uses the responses, recorded through a multistakeholder Delphi method to develop an MLP model for a socio-technical analysis of the current mobility regime and its potential transition pathways towards CAV future. The Delphi method is utilised in the project in order to elicit expert views onto a range of technological, societal, ethical and economic aspects of defined CAV services in the sphere of individual mobility, public transport, logistics and specific services. The article does not follow the standard Delphi methodology to an extent, i.e. developing the scenarios through qualitative or quantitative analyses, such as consensus, mean, media, frequency and cluster (Melander, 2018, p. 70).

For the analysis we used only the responses recorded in the first three-round phase of the Delphi method, which we used in order to develop a basic map of socio-technical scenarios of the future autonomous mobility systems. Given the generally low overall and technical knowledge of the operation, possibilities, pitfalls and development in the area of autonomous vehicles' technologies, the first phase includes primarily the experts, directly involved in research or development of different autonomous vehicles technologies (such as sensors or systems). On the other hand, this might bring about a systematic bias within the answers, such as optimism bias, also possibly magnified by a low number of participating experts, when compared to reference studies from a recent metastudy (Melander, 2018, p. 72).

\section{RESULTS - DEVELOPMENT OF THE SCENARIO PATHWAYS}

\subsection{Analysis of the first round: Identified key factors}

In the analysis of the first round of the Delphi study, we developed a list of key issues for the reference year of 2030 through open qualitative coding. The codes were further structured based on various factors, such as SAE levels of automation (SAE International, 2018). The issues have included (the list is not exhaustive) the following (figure 3).

\subsection{Analysis of the second round: Identified transition pathways}

The experts' views were clustered into three qualitative descriptions (storylines) (see Figure 4) of the future, based on proximity of their views on each topic, in order to further explore the reasoning and the actors and relations behind each scenario in the following rounds. The scenarios are further analysed through the multi-level perspective (Geels \& Schot, 2007), in order to identify the main pressure drivers, windows of opportunities and uncertainties of autonomous transition and its form.

Except for exceptionally fast technological progress, there is a very low probability of attaining the SC3 scenario, which would bypass the intermediary stage of conditionally automated vehicles.

\subsection{Identified landscape developments}

There are several major pressing factors identified already in the literature, that stabilise and destabilise the automobile regime - destabilising factors such as climate change, Peak Oil, or diffusion of ICT, and stabilising factors such as cultural preferences for ownership, speed, values, obduracy of physical landscape (urban structures etc.), macroeconomic growth and increasing demand for mobility (Geels, 2012b, p. 477). The factors were mostly reiterated throughout the recorded responses. The following are the main destabilising pressures, identified within the Delphi panel (figure 5). 


\section{Key issues}

Traffic
Technological and geographical aspects of the transformation of traffic flow and its parameters in different settings with various interventions for various levels of autonomy (preference or reserved lines, CAV-only zones, mixed traffic, infrastructure requirements).

Spatial requirements Requirements and barriers (such as infrastructure readiness, operating capabilities), to introducing the technology and services into various environments (gated zones, urban-suburban-rural setting, highways and motorways).

\begin{abstract}
Forms of ownership / Aspects of various forms of ownership and 'usership' (shared, private, mixed - institutional, usership cooperative, hybrid models (such as hybridisation of public-private transport) and community usage (such as technical services)).
\end{abstract}

\begin{tabular}{l}
\hline $\begin{array}{l}\text { Subsidies - parking } \\
\text { and supporting } \\
\text { infrastructure }\end{array}$ \\
\hline $\begin{array}{l}\text { Technological } \\
\text { development }\end{array}$ \\
\hline Specific technological \\
aspects
\end{tabular}
Aspects and impacts of implementing CAV preference in parking and traffic.

Time, technological and physical horizons of meeting the requirements for developing technologies as conditions for implementing respective levels of autonomy in various environments.

Addressing necessary conditions for developing specific technologies (perception - sensors, semantic classification, localisation; virtual and physical infrastructure - world model, etc.).

\begin{tabular}{ll}
\hline Public space & Impacts of implementation of CAVs onto public space availability and valuation. \\
\hline User acceptance & $\begin{array}{l}\text { Evaluation of potential user acceptance issues (safety, reliability, ownership, comfort, price, issues } \\
\text { with vehicle sharing), and common themes of user acceptance of the prototypes in the world. }\end{array}$ \\
\hline $\begin{array}{l}\text { Impacts on } \\
\text { employment }\end{array}$ & Including potential legislative regulations. \\
\hline
\end{tabular}

Environmental Including land-use changes, emissions, carbon life-cycle, etc.

impacts

\begin{tabular}{ll}
\hline Vehicle fuel types & Potential pressure of CAVs to support the electrification of vehicle fleet and infrastructure. \\
\hline Safety & $\begin{array}{l}\text { Impacts of CAVs on safety in different scenarios, depending on the speed, type of traffic, usership, } \\
\text { virtual safety, requirements of in terms of legislative changes/amendments }\end{array}$ \\
\hline
\end{tabular}

\begin{tabular}{ll}
\hline General legislation & $\begin{array}{l}\text { Requirements of CAVs in terms of the general legislative changes and possible barriers to } \\
\text { implementing new legislation on urban/national/European level. }\end{array}$
\end{tabular}

Urban governance Identification of possible early adopters of CAV technologies and the character of the deployed
acceptance services/technologies; the role of subventions; or vice versa, possible antagonists.

Political support Identification of main political actors and barriers and facilitators to support/thwart CAVs implementation (such as low public acceptance or industrial pressures).

\begin{tabular}{l} 
Testing \\
\hline $\begin{array}{l}\text { Economical } \\
\text { effectivity pathways }\end{array}$
\end{tabular}

User costs Dynamics of costs for the user, depending on costs of the services, public subsidies, environment,
ownership models and others.

\begin{tabular}{ll}
\hline User groups & Accessibility of CAVs to various socio-demographic groups. \\
\hline Core actors & $\begin{array}{l}\text { Actors, leading the transition in terms of real-world deployment of the services (e.g. a model of } \\
\text { "market rules", "central coordination" or a "thousand flowers" model of many decentralised } \\
\text { innovations and actions (Bolton \& Foxon, 2015, pp. 171-172)). }\end{array}$ \\
\hline
\end{tabular}

Time horizons Probability of achieving various stages of regime transition.

\begin{tabular}{ll}
\hline Velocity & Technical capability of achieving certain velocities under various conditions-environments.
\end{tabular}

Service operability Technical capability of implementing certain services under various conditions-environments. 


\section{Scenarios for \\ 2030's future \\ urban mobility}

\begin{tabular}{lll}
\hline SC1 & Reproduction & Implementation is hindered due to the co-occurrence of legislative, technical, \\
A sceptical-public & process / & infrastructural barriers, slow technological advance in developing vehicles in higher \\
transportpathway & $\begin{array}{l}\text { Transformation } \\
\text { path }\end{array}$ & $\begin{array}{l}\text { levels of SAE and resulting low public acceptance. Higher-level CAVs are implemented } \\
\text { to a limited extent only in public transport, operating on fixed lines and do not carry the } \\
\text { necessary momentum for a wider regime reconfiguration. }\end{array}$ \\
\end{tabular}

\begin{tabular}{lll}
\hline SC2 & Reconfiguration & Slow technological advance limits higher level mixed traffic implementation. \\
A slow & Autonomisation/automatisation proceeds as a gradual process towards higher SAE \\
incremental & levels - new vehicle capabilities with slow market penetration. CAVs operate in low \\
development & speeds only in restricted zones; innovations are adopted as hybridisations of old and \\
pathway & new and as local solutions to a limited extent - e.g. as a last-mile transport in larger \\
& residential zones.
\end{tabular}

\begin{tabular}{lll}
\hline SC3 & $\begin{array}{l}\text { De-alignment } \\
\text { A techno-optimist } \\
\text { pathway }\end{array}$ & $\begin{array}{l}\text { Autonomous vehicles are fully developed according to the Geels \& Schot criteria } \\
\text { (Ge-alignment / } \\
\text { Technological } \\
\text { substitution }\end{array}$ \\
& $\begin{array}{l}\text { without the necessity of C-ITS (cooperative intelligent transport systems) infrastructure } \\
\text { and driverless public transport for urban/transit. The diffusion of the CAVs depends } \\
\text { on the pace of technological progress, but given their great competitive advantage, } \\
\text { replacement rates are steep. Depending on the landscape pressures and pace of the } \\
\text { progress, the pathways unfold as either fast technology substitution (i.e. steep curve } \\
\text { of CAVs' market penetration) or automobile regime disruption and subsequent } \\
\text { 'autonomous' re-alignment, with major second-order impacts. }\end{array}$ \\
&
\end{tabular}

\section{Figure 4: Scenarios for 2030'future of urban mobility}

1. Cultural preferences and values are of special importance specifically to autonomous vehicles. Considering the relatively short horizon and low pace of vehicle fleet renewal in the Czech Republic and growing rate of automobilisation, there is a low tendency towards the abandonment of preference of privately owned and privately driven vehicles in the near future, even if interest in shared mobility is constantly growing. Another significant factor is the perceived lack of control over the vehicle and degradation of driver's capabilities, leading to reduced ability to deal with prompts to take control of the vehicle and reduced perceived ability to drive. There are also other similar strong cultural factors: physical safety concerns (safe behaviour towards VRUs might collide with safe behaviour towards CAV occupants); digital safety concerns (e.g. data leaks, hacking the vehicle's operation, opposition to surveillance and automatized rule enforcing, such as speed control). Socio-demographic variables' impact on CAV acceptance is further variegated - depending on nuanced factors, such as forms of interaction with the vehicles, or presence of experienced personnel (in PT AV).

2. Global environmental pressures, aligning with second- to third-order effects of automobility, such as land-use pressures and patterns, GHG emissions or growing rates of individual mobility.

3. Infrastructure readiness - while some of the technologies, that are being developed and implemented (such as 5G network) can support the autonomous vehicles deployment, crucial parts of the physical/digital infrastructure (such as real-world maps) are specific to the autonomous vehicles, and their implementation might be hindered primarily by institutional delays (e.g. conflicting responsibilities for roads of different categories), especially when considering autonomous, rather than CAVs.

4. Pressures to connect the vehicles through ITS with strong federal support of the EU. While this is not necessarily a hindrance, it might slow down the implementation of the CAVs outside the cities and main corridors.

5. Legislative-responsibility pressures - not being able to attain the full level of autonomy, due to critical issues of responsibility and safety in fringe situations, inherited from the existing legislature.

6. Lower driving performance in terms of speed and ability to directly control the pace of the vehicle and routing, associated with reduced driving pleasure. 


\section{Followed by the stabilising pressures:}

1. Existing pressures to further harmonise transport and urban transformations on the European level. This, while unpredictable in its form, entails pressures to harmonise legislation and financial incentives and probably strongly supports CAV implementation.

2. Growing pressure to reduce GHG performance of the transportation system, supporting the EV transition due to expected energy expenditure needs of CAVs.

3. Alignment of CAV development with technological progress and investment into their research.

4. Increased demand for mobility, coupled with urban structure, built to fit the individual car transportation;

5. Increased value of travel time by reducing the necessity to drive and enhancing connectivity.

6. The above is coupled with growing rates of IoT-activity monetisation, i.e. capitalising on the time and activities, spent in the vehicle, either directly, through providing services, or indirectly through data collection.

\section{Figure 6: Stabilising factors of automobile regime}

\section{The institutional} framework

The institutional framework, concerning laws and rules of mutually interdependent driving practices and infrastructure development. The framework includes an extensive network of actors, managing planning, development, sustaining, financing and evaluating the physical and digital infrastructure, as well as creating and enacting the laws and rules of its usage. For a successful transition, the autonomous mobility regime has to coordinate vast gradual changes, closely connected to the actual technological development. On the other hand, the proverbial race to the top of deregulation of testing and implementation of CAV pilots (e.g. CAVs permeating the traffic without being marked as such, or cutting back the requirements for loop testing) creates caveats on its own (see e.g. (Marres, 2018)). Testing, especially street testing may raise concerns, especially if connected to traffic accidents - even if not caused by the vehicle itself.

The material network
The material network of roads and spatial structures that stabilises certain mobility practices is a significant factor, especially if introduces restrictions and trade-offs (such as speed vs safety, or designated lanes vs public space) due to technological advancement, or lack thereof. On the other hand, growing land-use pressure, especially in bigger cities, is a strong factor towards reducing the space requirements of private car mobility. The CAVs have a strong synergy with other parking regulation and management niches and therefore better control of their space requirements.

\section{Conflicts of mixed traffic rules}

\section{Mixed traffic of manual vehicles and vehicles with varying degrees of automation still requires} a standardised, rule- and infrastructure-based operation. This creates conflicts, especially when traits of CAVs' traffic behaviour is predicted and taken advantage of by other road users, and further disrupts traffic flow and efficiency.

\section{The paradigm shift in data-based urban planning}

Vast databases on the infrastructure and traffic flows are gradually being utilised for more effective and precise urban and transport planning. Along with pressures of new mobility practices, this creates a paradigm shift in urban mobility planning, which leads to growing differences and potential between early CAV adopters and non-adopters.

\section{The network of} industry actors

\section{The network of industry actors - both new and incumbent. While in respective sectors of development,} such as semantic segmentation or sensor efficiency improvement, are many competing actors, production of operable vehicles in scale is a much expensive and challenging task to achieve. Still, given a large number and variability of start-up companies in the field, a less deregulated environment might allow much more developers, manufacturers, service providers and aftermarket modifications onto the field.

\section{Sunk costs of the previous regime}

Behaviour towards
CAVs
Sunk costs on different levels (technical expertise, ownership of vehicles, obsolete infrastructure).

Potential of other road users to take advantage of CAVs with a relatively low level of assertiveness, especially (or exclusively) towards vulnerable road users. This could positively affect active modes of transport (reducing the fear of collision) and increase pressure towards expanding the network of segregated cycling infrastructure.

\footnotetext{
Operational aspects Stabilisation of operational aspects of early, experimental niche practice (such as free parking) (see of the experimental Docherty, Marsden, \& Anable, 2018, p. 7), or their negotiation and disruption (such as the case of free phase parking space for shared bicycles).
} 


\begin{tabular}{lll}
\hline Niche & Description & $\begin{array}{l}\text { Supporting (stabilising) and hindering (destabilising) } \\
\text { multi-level factors }\end{array}$
\end{tabular}

N1 Lower-level automation functions (in general

First/Last mile 3 or 4 SAE, depending on the form) open up solutions possibilities for hybridisation of currently existing services: first/last-mile carsharing with low-speed, zone-restricted autonomous arrival. Outside the designated zones, the vehicles continue in manual/lower automation mode, depending on the route.

+ Synergy with gradual propagation of low-speed zones in the Czech Republic

+ Support of active transport modes thanks to supporting more fluent, less intensive traffic and space for traffic calming measures in the urban cores, that aide also the CAVs operation.

+ Intermodal connection to high-capacity PT supports utilisation rates of both modes.

- Low public acceptance of supporting measures (e.g. low-speed zones).

\begin{tabular}{|c|c|}
\hline $\begin{array}{l}\mathbf{N} 2 \\
\text { Integrated// } \\
\text { multimodal } \\
\text { transport }\end{array}$ & $\begin{array}{l}\text { Connected to high-capacity public transport } \\
\text { routes. This, along with pressure to optimise } \\
\text { utilisation rates, might support higher occupancy } \\
\text { rates, especially for longer fixed routes. }\end{array}$ \\
\hline $\begin{array}{l}\mathbf{N} 3 \\
\text { Carsharing and } \\
\text { ridesharing } \\
\text { enhancement }\end{array}$ & $\begin{array}{l}\text { Enriching the growing carsharing market - } \\
\text { higher level SAE functions, such as self- } \\
\text { parking, self-refuelling or recharging. Utilising } \\
\text { rich data from the vehicles and users for } \\
\text { demand/mobility management: more effective } \\
\text { distribution of trips, reducing idle time, parking } \\
\text { requirements, increasing occupancy rates. }\end{array}$ \\
\hline
\end{tabular}

+ Available policy support through measures, such as park-and-ride.

- A lack of cooperation between service providers.

- Lower acceptance due to carriage reloading and time loss.

+ A growing market of partnerships of the cities with TNCs.

+ Reducing operating costs, allowing for a faster mass launch of the more expensive services

+ To an extent a continuation of a "car culture", especially for car sharing

- Ridesharing has to overcome the factor of unwillingness to share restricted space with strangers and a general problem of assigning responsibility to a specific driver in case of a need to take over the manual control.

- A tendency to substitute for public transport and transit routes, endangering connectivity of less accessible regions.

- Increased traffic intensities and congestions, especially if contributing to PT disruption.

$\begin{array}{lll}\text { N4 } & \text { The niche of "connected highways", allowing } & \text { + Synergy with C-ITS development, providing safety } \\ \text { Connected } & \text { fully autonomous driving through whole } & \text { benefits also for manual vehicles (e.g. Early Warning, } \\ \text { (C-ITS) } & \text { capacity or designated lanes of high-capacity } & \text { object detection in worsened visibility). }\end{array}$

highways

roadblocks in vehicles' capabilities development (e.g. operability in bad weather/road conditions, C-ITS malfunction fallback, or interaction with VRUs), are proposed: e.g. adapting the level of automation to the external conditions, teleoperating, or connected vehicles' platooning in worsened weather conditions.

\begin{tabular}{|c|c|c|}
\hline $\begin{array}{l}\text { N5 } \\
\text { Public } \\
\text { transport }\end{array}$ & $\begin{array}{l}\text { Public transport schemes - ranging from fully } \\
\text { autonomous public transport vehicles (already } \\
\text { deployed on rails); to on-demand fixed-route } \\
\text { automated linkages to mass high-speed transit } \\
\text { routes; to demand-responsive bus services; to } \\
\text { slow-speed microbuses, that are already being } \\
\text { tested. }\end{array}$ & $\begin{array}{l}\text { + A faster implementation allowed by reserved (bus) } \\
\text { lanes, or strengthening of priority on the (tram) rails, } \\
\text { improved modal efficiency } \\
+ \text { Supported by urban governance, when reducing costs } \\
\text { of providing or expanding PT effective network. } \\
+ \text { Aligned with integrated regional and national transport } \\
\text { planning, allowing to prepare more effective plans, } \\
\text { based on data collected. } \\
+ \text { Effectivity and attractivity enhanced by ITS } \\
\text { development and data collection. } \\
\text { - Diminishing viability outside the urban core or for } \\
\text { regions with less developed infrastructure. }\end{array}$ \\
\hline $\begin{array}{l}\text { N6 } \\
\text { Complementary } \\
\text { logistic services }\end{array}$ & $\begin{array}{l}\text { Such as automated delivery to the CAV's cargo } \\
\text { space. }\end{array}$ & $\begin{array}{l}+ \text { Increases delivery effectivity, reduces VKT and time } \\
\text { loss, increases vehicle utilisation }\end{array}$ \\
\hline
\end{tabular}




\subsection{Regime dynamics under diverse socio-technical scenarios}

There are two interdependent regimes under discussion - one is the currently dominant private automobility regime and the second is the transitioning autonomous regime. Within the CAV development, we have identified the dominant constituents of the transitioning regime (figure 7 ).

\subsection{Identified viable niche developments for the year 2030}

The niche developments were conceptualised and identified through the questionnaires as categories and viable business models of mobility services such as autonomous public transport, ridesourcing/carsharing/ridesharing, logistics and specific services (such as technical services) - operating in the urban environment, that have potential to dominate a specific market sector. While there can be myriads of services, that operate under the protection of long-term investments, there is little chance, that these services can persist in the same form considering their price per mile performance. Hence, the niches, identified through the Delphi study, were selected further linked to the supporting actors and environments, as well as to shifts in individual practices in order to increase the reliability of the results. These are the niche developments that were identified, along with their multi-level supporting and hindering factors, pressures and synergies (figure 8).

\section{POLICY TRANSFER - APPLICATIONS FOR PUBLIC POLICIES TO SUPPORT SUSTAINABLE TRANSITIONS}

The aim of the article was to explore the potential arrangements of mobility services and policies in order to maximise the broader common sustainability goals, i.e. low-carbon and socially equitable mobility. We have identified the broad principles of such arrangements, based on the research results - the opportunities and drawbacks that are common for the scenarios:

1. Searching for synergies with public and active modes of transport, rather than allowing a new network of individual car transportation to emerge and proliferate.
The main conclusion, based on the regime dynamics analysis is, that only transforming the incumbent individual car regime can further disrupt effective PT network and exacerbate passive transport lifestyle, reverberating into further second-order effects, such as car dependence and accessibility of peripheral regions. On the other hand, there is a strong potential, when coupled with demand management and traffic management measures, such as congestion charging, to promote multimodal active and public transport. In general, slower and more fluent traffic suits both the CAVs and cyclists or pedestrians, even if for different reasons. This is contradicted by a strong landscape pressure towards faster, individual mobility, translating to low public acceptance. Therefore, other alliances have to be sought - increased pressure towards reducing environmental and health impacts on the landscape level, shifting cultural preferences and urban planning practices on the regime level or support of sustainable local actor coalitions on the niche level.

2. Data acquisition and utilisation. In order to assess the effects of services' implementation and avoid the growing gap between public and private information on the urban life, the urban governance should negotiate access to aggregated data, collected through vehicles' operation, as well as further promote transparent rich transport data collection and analysis.

3. Minimal standards of service provision whereas experimental, pilot operations of CAV concentrate on the individual level of service, rather than overall transport system performance, they tend to replicate existing problems and inequalities, such as equity of access. The niche projects should act on the principles of sustainable mobility and be implemented as a meaningful part of the urban transportation system, rather than to disrupt and observe.

4. Long term planning with uncertainties in mind: infrastructure investments, coupled with urban spatial planning, are a strong stabilising factor that locks-in a specific pathway for a long time. The same applies to public transport disruption - a vicious circle 
of public transport abandonment and car dependency strengthening. Development of CAV technologies allows bypassing some of the lock-in barriers by allowing more hybrid and flexible solutions, such as fleets of mid-capacity buses that are goal-oriented (i.e. providing accessibility, occupancy, costeffectiveness or externalities reduction).

\section{DISCUSSION}

Through analysing the aspects of stabilisation or destabilisation of automobility regime, the aim of the article was to point out a specific political, social and institutional, technological and material aspects of urban mobility in Czech Republic that might swerve the direction of CAV implementation towards one that is more socially equitable and environmentally neutral. The utilisation of Delphi study results for the development of a multi-level perspective sociotechnical transition roadmap is a promising method when attempting to explore and elaborate the connections between elements and actors of the analysed technology. While the method does not operate with probabilities, it uses the exploratory and reflective nature of the Delphi method process to develop a network of forces, relations and dependencies, to an extent akin to system dynamics approach. Based on a three-round expert Delphi panel responses, we propose three possible scenarios for socio-technical regime transition to autonomous mobility, the feasibility of which depends mostly on landscape factors, such as technological progress and public acceptance. For these three pathways, we have identified the regime transition dynamics and space for viable niche innovations, connecting stabilising and destabilising factors and possible actor-coalitions on multiple levels. The most significant shortcoming of the research method is the small sample of participants. While predictive model, informed by expert discussions and re-formed by multilevel dynamics of innovation pathways, allows for more detailed and adaptive policy creation, than expert advisory groups, a larger and more heterogeneous sample of experts is needed for a further study to confirm and explicate the preliminary results.

The objective of the research was primarily to aid the urban mobility planners and institutions involved in long-term urban planning. From the identified scenarios we devise a broad space for possible policy actions, supporting a more sustainable urban autonomous transition. However, due to mounting uncertainties, it is yet not possible to predict, whether the autonomous vehicles will align more with the currently highly unsustainable automobile regime, only slightly rearranging its operation, or whether it will open up a space for other innovations, thanks to reduced traffic intensities and increased safety.

Acknowledgements: This work was based on a data acquired through TACR project no. TL01000530 and with the financial support of the Ministry of Education, Youth and Sports as part of the National Sustainability Programme I, project of Transport R\&D Centre (LO1610) on the research infrastructure acquired from the Operational Programme Research and Development for Innovation (CZ.1.05/2.1.00/03.0064).

\section{REFERENCES}

Adam, B., \& Groves, C. (2007). Future Matters: Action, Knowledge, Ethics. BRILL.

Altrock, U., Güntner, S., Huning, S., \& Peters, D. (2019). Spatial Planning and Urban Development in the New EU Member States - Between Adjustment and Reinvention.

Barr, S., \& Prillwitz, J. (2014). A Smarter Choice? Exploring the Behaviour Change Agenda for Environmentally Sustainable Mobility. Environment and Planning C: Government and Policy, 32(1), 1-19. https://doi.org/10.1068/c1201

Bolton, R., \& Foxon, T. J. (2015). A socio-technical perspective on low carbon investment challenges - Insights for UK energy policy. Environmental Innovation and Societal Transitions, 14, 165-181. https://doi.org/10.1016/j.eist.2014.07.005

Castiglione, J., Cooper, D., Sana, B., Tischler, D., Chang, T., Erhardt, G., ... Mucci, A. (2018). TNCs \& Congestion. Civil Engineering Reports. Retrieved from https://uknowledge.uky.edu/ ce_reports $/ 1$

Currie, G. (2018). Lies, Damned Lies, AVs, Shared Mobility, and Urban Transit Futures. Journal of Public Transportation, 21, 19-30. https://doi.org/10.5038/2375-0901.21.1.3

Dennis, K., \& Urry, J. (2009). After the Car. Polity.

Docherty, I., Marsden, G., \& Anable, J. (2018). The governance of smart mobility. Transportation Research Part A: Policy and Practice, 115(C), 114-125.

Elzen, B, Geels, F., \& Hofman, P. (2002). Sociotechnical Scenarios (STSc): Development and evaluation of a new methodology to explore transitions towards a sustainable energy supply.

Elzen, Boelie, Geels, F. W., \& Green, K. (2004). System Innovation and the Transition to Sustainability: Theory, Evidence and Policy. Edward Elgar Publishing. 
Geels, F. W. (2012a). A socio-technical analysis of low-carbon transitions: Introducing the multi-level perspective into transport studies. Journal of Transport Geography, 24, 471-482. https://doi.org/10.1016/j.jtrangeo.2012.01.021

Geels, F. W. (2012b). A socio-technical analysis of low-carbon transitions: Introducing the multi-level perspective into transport studies. Journal of Transport Geography, 24, 471-482. https://doi.org/10.1016/j.jtrangeo.2012.01.021

Geels, F. W. (2014). Regime Resistance against Low-Carbon Transitions: Introducing Politics and Power into the Multi-Level Perspective. Theory, Culture \& Society, 31(5), 21-40. https:// doi.org/10.1177/0263276414531627

Geels, F. W., \& Schot, J. (2007). Typology of sociotechnical transition pathways. Research Policy, 36(3), 399-417. https://doi. org/10.1016/j.respol.2007.01.003

Golub, A., L. Hoffmann, M., E. Lugo, A., \& F.Sandoval, G. (2016). Bicycle Justice and Urban Transformation: Biking for all?, 1st Edition (Hardback) - Routledge. Retrieved from https://www.routledge.com/Bicycle-Justice-and-Urban-Transformation-Biking-for-all-1st-Edition/Golub-Hoffmann-LugoSandoval/p/book/9781138950245

Graham, S., \& Marvin, S. (2001). Splintering Urbanism: Networked Infrastructures, Technological Mobilities and the Urban Condition. Psychology Press.

Grush, B., \& Niles, J. (2018). The End of Driving: Transportation Systems and Public Policy Planning for Autonomous Vehicles. Elsevier.

Landeta, J., \& Barrutia, J. (2011). People consultation to construct the future: A Delphi application. International Journal of Forecasting, 27(1), 134-151. https://doi.org/10.1016/j.ijforecast.2010.04.001

Linstone, H. A., \& Turoff, M. (1977). The Delphi Method: Techniques and Applications. Addison-Wesley Publishing Company, Advanced Book Program.

Marres, N. (2018). What if nothing happens? Street trials of intelligent cars as experiments in participation.

Melander, L. (2018). Scenario development in transport studies: Methodological considerations and reflections on delphi studies. Futures, 96, 68-78. https://doi.org/10.1016/j.futures.2017.11.007

Nikolaeva, A., Adey, P., Cresswell, T., Lee, J. Y., Nóvoa, A., \& Temenos, C. (2019). Commoning mobility: Towards a new politics of mobility transitions. Transactions of the Institute of British Geographers, 44(2), 346-360. https://doi.org/10.1111/ $\underline{\operatorname{tran} .12287}$

Nunes, A., \& Hernandez, K. D. (2019). Autonomous Vehicles and Public Health: High Cost or High Opportunity Cost?

Roy, S. (2019). QUANTIFYING THE IMPACT OF TRANSPORTATION NETWORK COMPANIES (TNCs) ON TRAFFIC CONGESTION IN SAN FRANCISCO. Theses and Dissertations--Civil Engineering. https://doi.org/10.13023/etd.2019.186

SAE International. (2018). Taxonomy and Definitions for Terms Related to Driving Automation Systems for On-Road Motor Vehicles. https://doi.org/10.4271/J3016_201806
Sheller, M. (2015). Racialized Mobility Transitions in Philadelphia: Connecting Urban Sustainability and Transport Justice. City \& Society, 27(1), 70-91. https://doi.org/10.1111/ ciso. 12049

Temenos, C., Nikolaeva, A., Schwanen, T., Cresswell, T., Sengers, F., Watson, M., \& Sheller, M. (2017). Theorizing Mobility Transitions: An Interdisciplinary Conversation. Transfers, 7(1). https://doi.org/10.3167/TRANS.2017.070109

Turoff, M. (1970). The design of a policy Delphi. Technological Forecasting and Social Change, 2(2), 149-171. https://doi. org/10.1016/0040-1625(70)90161-7 